\title{
Correction to: Not Just Lying to Oneself: An Examination of Bad Faith in Sartre
}

\author{
Stalin Joseph Correya ${ }^{1}$ (D)
}

Published online: 7 May 2021

(C) ICPR 2021

\section{Correction to: Journal of Indian Council of Philosophical Research (2021) 38:103-121 https://doi.org/10.1007/s40961-021-00232-y}

Few errors have been introduced in the online published article. The corrections have been incorporated in the points given below.

1. On page no. 2 of the Online First article (page no. 104 in the issue to which assigned), instead of Sect. 2 of Part I of BN it says "Conclusion" section of Part 1 of $B N$.

2. On page no. 2 (no. 104 in the issue), instead of Sect. 1 of Part I of $B N$, it says "Introduction: The Problem of Bad Faith" section of Part 1 of $B N$.

3. On page no. 18 (no.120 in the issue), instead of Sect. 1 of Part III of $B N$, it says "Introduction: The Problem of Bad Faith" section of $B N$.

Publisher's Note Springer Nature remains neutral with regard to jurisdictional claims in published maps and institutional affiliations.

The original article can be found online at https://doi.org/10.1007/s40961-021-00232-y.

Stalin Joseph Correya

stalincorreya@gmail.com; stalinjosephcorreya@iitb.ac.in; correyastalin@gmail.com

1 Department of Humanities and Social Sciences (HSS), Indian Institute of Technology Bombay,

Powai, Mumbai, Maharashtra 400076, India 